\title{
Protecting Ideas: Ethical and Legal Considerations when a Grant's Principal Investigator Changes
}

Leonidas G. Koniaris, MD (1); Mary I. Coombs, JD (2); Eric M. Meslin, PhD (3); Teresa A. Zimmers, PhD (1)

From the:

1) Department of Surgery, University of Indiana School of Medicine, Indianapolis, IN

2) School of Law, University of Miami, Miami FL

3) Indiana University Center for Bioethics, University of Indiana School of Medicine, Indianapolis IN.

\section{Address all correspondence to:}

Leonidas Koniaris, MD

Indiana University School of Medicine

45 Barnhill Drive; Emerson 5

Indianapolis, IN 46202

Phone: 317-278-7778

Fax: 317-278-4897

E-mail: lkoniari@iu.edu

Keywords: grant transfers, grant stipulations, grant awards, principal investigator, PI transfer, authorship, plagiarism

Running Title: Ethical and Legal Considerations when Changing a PI

This is the author's manuscript of the article published in final edited form as:

Koniaris, L. G., Coombs, M. I., Meslin, E. M., \& Zimmers, T. A. (2015). Protecting Ideas: Ethical and Legal Considerations When a Grant's Principal Investigator Changes. Science and Engineering Ethics, 1-11. http://doi.org/10.1007/s11948-015-9688-3 
Dr. Koniaris is professor of surgery and Vice Chair of Research, Department of Surgery, Indiana University School of Medicine, Indianapolis, IN.

Email: Ikoniari@iu.edu

Dr. Mary Coombs is professor emeritus of law and former president of the faculty senate at the University of Miami School of Law, University of Miami, Miami, FL.

Email: mcoombs@law.miami.edu

Dr. Eric M. Meslin is professor of bioethics, Associate Dean and founding director for the Indiana University Center for Bioethics, Indianapolis, IN.

Email: emeslin@iu.edu

Dr. Teresa A. Zimmers is associate professor in the departments of Surgery and Cell Biology \& Anatomy at Indiana University School of Medicine, Indianapolis, IN.

Email: Zimmerst@iu.edu

Potential conflicts of interest: LGK has transferred a grant to another investigator. 


\section{ABSTRACT}

Ethical issues related the responsible conduct of research involve questions concerning the rights and obligations of investigators to propose, design, implement, and publish research. When a principal investigator $(\mathrm{PI})$ transfers institutions during a grant cycle, financial and recognition issues need to be addressed to preserve all parties' obligations and best interests in a mutually beneficial way. Although grants often transfer with the $\mathrm{PI}$, sometimes they do not. Maintaining a grant at an institution after the PI leaves does not negate the grantee institution's obligation to recognize the PI's original ideas, contributions, and potential rights to some forms of expression and compensation. Issues include maintaining a role for the PI in determining how to take credit for, share and publish results that involve his or her original ideas. Ascribing proper credit can become a thorny issue. This paper provides a framework for addressing situations and disagreements that may occur when a new PI continues the work after the original PI transfers. Included are suggestions for proactively developing institutional mechanisms that address such issues. Considerations include how to develop solutions that comply with the responsible conduct of research, equitably resolve claims regarding reporting of results, and avoid the possibility of plagiarism. 


\section{INTRODUCTION}

A grant award is a significant, positive event for the principal investigator (PI), co-

investigators, other laboratory members, sponsoring department and sponsoring institution. The award may represent years of effort and discovery on the PI's part-and obtaining the award is often predicated on how promising a review board deems the Pl's preliminary data and original ideas to be.

Despite how heavily vested the PI is in the institution and the research funded by the grant, the PI might move to a different institution during the funding period, for a number of reasons. These may include perceived personal or career growth opportunities for the $\mathrm{PI}$, such as career advancement, salary increases, or a potentially more productive scientific environment. The career needs of the Pl's domestic partner may drive the decision. The PI's fixed-duration employment contract may expire, or the PI may regrettably fail to obtain the institution's required academic advancement.

Regardless of the reason, when a move occurs, one might assume that the awarded grant would transfer with the PI. While that often happens, it is not categorically the case. If a PI transfers to another facility during the course of that grant-funded research, transfer of the funds, plus his or her ownership of original ideas can pose multiple challenges. Understanding all the stakeholders, as well as the legal and ethical implications of transfers, can help facilitate decisions that are in the best interest of everyone involved. 
Legal precedent (Stanford v. Roche, 2011; CGR 2011a), grant provisions (NIH 2010a; State of California 2014), and institutional policies often stipulate that the financial award for most grants is the property of the institution to which the grant is awarded. However, transfer or retention of funds is only one aspect of the equation. Although discoveries stemming from work as an employee or faculty member normally are either shared or assigned entirely to the host institution as a condition of employment (nolo.com), such issues can become murky when a PI transfers, particularly if the grant remains with the grantee institution. Thus, ownership of original ideas, authorship of published results, and potential claims regarding patents resulting from that research need to be addressed before a transfer occurs.

To date, little has been written about the ethical and legal issues surrounding grant/PI transfers. This article seeks to fill that gap by suggesting how institutions can define principles and establish processes to avoid or address conflicts that may arise among the parties involved with a funded grant when the PI moves. This article introduces the typical grant and its stakeholders, then examines decisions related to transferring, retaining, or terminating a grant. Issues regarding publication of results when grants are not transferred are also examined.

\section{THE GRANT AND ITS STAKEHOLDERS}

\section{The grant}

In this article, a grant is defined as any award of monies to support research or scholarly endeavors. Grant monies may originate from for-profit or non-profit entities, state or 
federal agencies. This article concentrates on federal grants to universities; however, the principles described herein should apply to most non-federal grants also.

Grant monies fund both direct and indirect costs for a research project. Direct funds support the investigative team's salary, equipment, and other expenses linked solely to the performance of the research specified in the awarded grant. Indirect funds support infrastructure needed to undertake such activities including facilities and administrative costs. Such items cannot be linked solely to the research project. Indirect amounts generally are calculated as a fraction of the direct award amount. For most federally funded grants, the cost for indirect support ranges from $50 \%$ to $70 \%$ of the direct amount (GAO 2013). As indirect funds are intended to support research infrastructure in general, they can be a very beneficial source of revenue for an institution.

Grants may also be classified based upon the principal investigator's role in the genesis of the grant. Grants that involve the principal investigator's novel ideas, with or without additional input from others, are termed investigator-initiated grants. Investigatorinitiated grant applications are generally assessed through a multistep peer review process and are awarded only to the highest-scored applications (NIH n.d.).

In contrast, non-investigator initiated grants are more like a fee-for-service arrangement (such as grants to participants in an industry-sponsored pharmaceutical trial). Alternatively, awards to center cores for carrying out a larger grant like a Research Program and Center Grant (termed P30 grants by the NIH) may arguably have 
components of both non-investigatorinitiated and investigatorinitiated grants $(\underline{\mathrm{NIH}} 2013)$.

Principal investigators on non-investigator initiated grants generally have little or no claim to the grant or its research results. This manuscript focuses on investigatorinitiated grants.

\section{The stakeholders}

\section{The sponsor/funding agency}

Grants are subject to the rules that their sponsor(s) or parent organization(s) set forth. Sponsors look to fund grant applications that most closely match the funding agency's scope of interest (NIH n.d.). For example, the National Institutes of Health (NIH) is the major sponsor of federally funded, investigator-initiated research in the U.S. NIH provided nearly $\$ 30.1$ billion dollars for research in 2014 (NIH 2015), which represents the second-highest outlay of R\&D monies in the federal budget (Sargent 2013).

Globally, any funding agency's policy and the particular grant may determine, or at least strongly influence, what happens if the PI changes institutions. For example, statesponsored awards may require that funded research take place at an institution within the state. Thus, if the PI were to move to an out-of-state institution, the grant would not transfer. Similarly, grants that support enhanced research infrastructure at an institution (such as NIH's G-series grants) (NIH 2013), are generally retained by the institution to which they were awarded. In contrast, grants awarded to help develop the careers of researchers with high potential (such as NIH's K-series grants) generally move with the 
PI (NIH 2010a). While general criteria exist regarding grant transferability, additional criteria usually are specified when grant applications are solicited.

\section{The grantee (host) institution}

Grants typically are awarded to an institution (such as a university or non-profit research institute) on behalf of the $\mathrm{PI}$-not to the PI. Federal grant monies are the major means of financial support for research efforts at most U.S. institutions and abroad (Sargent 2013; Zinner 2009). The grantee institution's two-fold role is to (1) maintain an environment in which the research can succeed and (2) provide fiscal oversight for the grant, including accountability for its direct costs and indirect expenses (GAO 2013; CGR 2001).

\section{The principal investigator (PI)}

The PI is generally a faculty member at the host institution; he or she oversees the grant. For investigator-initiated grants, the PI is usually the individual who generated the major ideas, research methods/design, and/or did (or oversaw) the majority of the intellectual, experimental and organizational work that led to the successful grant award.

\section{Other potential stakeholders}

Co-investigators are other faculty involved with the grant. They may be staff at the host institution or other institutions. They may contribute ideas, techniques or other expertise that are essential to successfully executing part of the research project. Based on their 
roles, co-investigators may have a reasonable argument for continued involvement in and financial support from the grant if a transfer is contemplated.

Laboratory personnel are non-faculty scientists, fixed-duration contract researchers, and trainees (such as graduate students and post-doctoral fellows) who work under the $\mathrm{PI}(\mathrm{s})$ and co-investigator(s). Lab personnel generally do not have leadership roles in a grant but may expect compensation and mentoring that the grant supports. Lab personnel may transfer institutions with a $\mathrm{Pl}$; however, they may or may not continue to be supported by a grant, depending on whether it is retained in whole or in part, or is no longer associated with the same PI.

\section{GRANT DISPOSITION WHEN THE PI LEAVES THE INSTITUTION: PROCESSES}

\section{AND PERSPECTIVES}

Compliance to a grant's stipulations encompasses both management of funds awarded as well as the conduct of science (CGR 2001). Thus, each grant is subject to special considerations when a PI leaves an institution before a grant cycle is finished. Additionally, all federally funded research must be compliant with the Bayh-Dole Act, which identifies a duty of the funded investigators and institution to facilitate results (including inventions) be made commercially available to benefit the public (CGR 2011b; Henderson 2002).

\section{Financial Interests}


When a PI on an investigator-initiated grant moves, he or she may seek transfer of the grant to the new ("gaining") institution while the original institution may seek to retain it. Although the onus is on the PI to start the paperwork that requests a grant transfer $(\mathrm{NIH}$ 2010a), all parties involved must provide justification for where the grant should "live." A host institution wishing keep a grant needs to formally identify a faculty member who would become the new PI and file a request for that with the grant's sponsor. Conflict may arise when opinion differs regarding who will continue to be the PI or whether the grant should transfer.

It is almost always in the funding agency's best interests to continue the grant if it will still further the agency's goals and the proposed project can be completed. Where the project is completed may be a matter of debate.

\section{Grant Transfer and Completing the Proposed Projects}

A number of scenarios might influence the appropriateness of transferring a grant or retaining it at the original institution. The funding agency and all other parties involved in the grant's disposition should consider all of the following. (1) If the grant were to be retained at the initial institution, would the new $\mathrm{PI}$ and team be able to successfully complete the proposed work? (2) Similarly, if the PI were to maintain the grant at a new institution, would the new team and institution be able to complete the work? (3) Does the gaining institution have the infrastructure and resources needed to accomplish the grant's research goals? (4) Does that infrastructure include the ability to comply with needed protections of research subjects if applicable? (5) Do human subject protections 
differ between institutions; and, if so, do those differences run the risk of patient harm or weakening study endpoints?

An institution might seek to retain grant funding not only for the prestige of having promising research be attributed to their institution, but also for financial reasons. Grantfunded equipment often remains with the host institution unless the sponsor deems that the research cannot continue at the new institution without it (NIH 2010b). More importantly, funds for indirect costs can help support a variety of ongoing research efforts: by providing monies to support infrastructure, equipment and personnel. This support may help prevent attrition of research-associated faculty, and help support postdoctoral trainees and others who contribute to the host institution's overall research mission, which in turn indirectly facilitates future grant awards (GAO 2013). Also, because of the capital deposit at the beginning of the research cycle, grant awards may improve an institution's financial liquidity and stability. Such payments may enhance the institution's capacity to offer recruitment packages and capital outlays. Furthermore, academic rankings of research-focused schools, universities, and similar institutions are based, in part, on total extramural institutional funding (particularly that given for investigator-initiated research, such as NIH RO1s) (NIH 2013).

Ultimately, research and innovation fuel economic growth (Henderson 2002; Atkinson 2011) — and some potential income for universities if discoveries turn into licensing opportunities with industries (Stanford v. Roche 2011; CGR 2011a; NIH 2010a; Mangan 2000). Finally, government funding has been stagnant or declining in recent years 
(Sargent 2013; Atkinson 2011; Browning 2014). This adds pressure to administrators at all levels to retain grant monies. Thus, every research institution seeks to maintain or increase its total grant dollars.

Despite all those reasons for an institution to want to retain a grant, legitimate reasons exist for allowing a grant transfer. First, a research institution plays a critical societal role as a guardian of ideas (Lawrence 1990), as well as a servicer of information exchange (CGR 2011a; Faust 2010). Because research institutions are part of the larger society, it is common for researchers to change institutions. Indeed, universities frequently seek to recruit new faculty with records of stellar grant funding. Thus, recruiting institutions are interested in grants moving relatively freely with faculty PIs. Because the same institutions will predictably be both originating and transfer institutions, it may be in their long-term interests to accommodate a request to relinquish a grant when the PI moves.

\section{Recognition-based Interests}

When a grant is transferred, both financial and recognition-based interests are potentially at stake. Issues surrounding the latter are elucidated in the principles of responsible conduct of research set forth by the Office of Research Integrity (http://ori.hhs.gov/) and the International Committee of Medical Journal Editors (ICMJE; http://www.icmje.org/recommendations/).

These principles are widely accepted among academic groups and research institutions as standards for conducting research and publishing its results. Publishing guidelines 
are detailed in ICJME's Uniform Requirements for Manuscripts Submitted to Biomedical Journals (ICJME 1991; Uniform Reqs 2010). More details and real-world applications of those guidelines can be found in the latest edition of Shamoo and Resnik's Responsible Conduct of Research (Shamoo 2009).

The ethical conduct of research principles and terms of most investigator-initiated grants generally obligate the PIs to publish their results (e.g., in poster presentations, peerreviewed journals). Authorship on publications and in public presentations is reserved for those who are responsible for, and deserve credit for, the work. Specifically, authors are those who (1) make substantial contribution to the concept and design of the work, (2) draft the work or revise it critically for intellectual content, (3) approve the final version to be published, and (4) agree to be accountable for all aspects of the work (ICJME n.d.). Thus, for grants that involve novel ideas, all parties who are active members at the concept and design stage should be involved in reporting research results in any format. Furthermore, the ICMJE states that individuals with a substantial role in the conceptualization and generation of the ideas around a publication should be allowed the opportunity to participate in the research project. Thus it is improper to exclude such individuals from steps 2 through 3 . However, when a PI leaves and the grant remains with the grantee institution, that institution's and other investigator's obligation to ensure the continued involvement of the $\mathrm{PI}$ in publications varies, depending on the extent to which the results embody the original Pl's original ideas.

\section{When interests clash}


If research conducted by the new PI closely follows that of the original Pl's ideas, ethically, the original PI should be actively involved in the grant's ongoing research and its subsequent publication—and duly acknowledged for his or her role in the discovery of those ideas. Periodic communications between PIs can ensure that both forms of involvement occur appropriately. If the grant's focus changes under the new PI so that the results reflect the examination of new questions distinct from those posed by the original PI, the claim for involvement of the first $\mathrm{PI}$ is much weaker.

Philosophical differences may arise regarding what constitutes proper versus improper use of the original Pl's words and ideas (Bouville 2008). This begs the question of what constitutes plagiarism, which is misuse of large amounts of someone else's material in such a way that would mislead most readers as to the listed author's contribution. The Office of Research Integrity defines plagiarism as "theft or misappropriation of intellectual property and the substantial unattributed textual copying [ver batim, or nearly so] of another's work" (ORI 1994). Because of this, the Council on Governmental Relations and others recommend that research centers proactively develop policies to address "who owns what" in the event of a grant transfer, so that disputes may be resolved equitably to ensure fair recognition of the intellectual roles of all contributors (CGR 2011b; Harper 2007). The simplest way to avoid plagiarism is by including the original $\mathrm{PI}$ as an author throughout the writing and publication process.

A third point of contention with recognition is ownership of patents. As long as the grantee institution abides by the provisions of the Bayh-Dole Act (amended in 2000 by the Technology Transfer Commercialization Act) (Stanford v. Roche 2011), the grantee 
institution has the right to retain title to any invention conceived or first brought into practice using federal grant funds (NIH 2010a). In this sense, the first PI would be the "author/creator" and "custodian" of the ideas, processes, devices, organisms and/or data conceived and developed-and may be named as an inventor on any patent that emerges from that. But the grantee institution owns the results of the Pl's efforts. (On occasion, co-investigators and key lab personnel may also have a right to participate in patent applications, subject to contract-based employment verbiage regarding discoveries.)

\section{PROPOSED SOLUTIONS}

In the vast majority of grants, the host institution will agree to transfer a grant to the Pl's new institution. In instances where that institution seeks to retain the grant, one of two scenarios may transpire. Rarely, a grant may move in a significantly different direction than the original PI delineated. In that case, involvement of, and agreement by, the original PI may not be required. However, in the more common scenario, research under the grant continues under a new PI but relies on the first Pl's original ideas. For this latter scenario, we propose a four-pronged strategy:

(1) Develop processes and procedures to address such issues if they are not already in place (described in the following paragraphs); invoke when needed.

(2) Incorporate all stipulations of the grant in considering any disputes.

(3) Foster open dialogue among all stakeholders working on the grant.

(4) As needed, solicit input from an impartial third party, such as an ethics committee.

\section{Proactive policy development}


While most institutions have clauses in their conditions of employment regarding assignment of inventions, many do not have policies regarding the topics discussed in this paper. As a starting point, the granting agency's goals and objectives must be defined and understood, including the range of solutions that permit continued grant funding.

Importantly, institutional policies and procedures need to be clearly defined and in place (Browning 2014) before disputes arise. These should be created through a structure that includes input from faculty (such as special oversight committees set up by school councils or university senates) as well as senior institutional leadership. In addition to defining issues regarding retention or transfer of grants, the role of the original vs. new $\mathrm{PI}$ in reporting results should be defined explicitly as part of any transfer arrangement. Also, issues of scholarship, authorship, recognition and shared compensation (if royalties or licensing are involved) need to be addressed.

Thus, a major task for any oversight committee is to determine the degree to which the research—at any particular time—is intertwined with the Pl's original ideas. Answering that question can generate scenarios to identify under what circumstances the grant would be continued and what recognitions would be appropriate for all parties involved. Ideally, the university should recognize the first PI's key intellectual role in developing the ideas embodied in the funded research. As already noted, any resolution that does not recognize that PI's original ideas and allow him or her significant input in reporting 
those ideas is problematic with respect to responsible conduct of research principles and the potential for plagiarism.

Grant termination is a last resort if all involved parties cannot agree on direction and/or responsibilities. Any attempt to publish a highly contested work among contributors who have conflicting points of view will range from problematic to impossible. With the suggestions presented in this article, grantee institutions should be able to delineate acceptable solutions.

\section{Grant stipulations}

In addition to what has already been discussed about understanding grant stipulations, the following general tenets apply. Disputes over fee-for-service grants likely will be resolved by the sponsor, in consultation with the institution and/or the original PI. Disputes over investigator-initiated grants may require any combination of our four listed strategies.

\section{Open dialogue}

Good communication among all parties involved is key. Foster formal, open dialogue among the original PI, other investigators (particularly those whose activities were essential in obtaining the award), and departmental/institutional representatives.

Encourage everyone to articulate their interests and perspectives on what options would best help achieve the grant's objectives. Clearly define expectations regarding work in progress, oversight of future work and authorship of that work, as well as the best ways 
to communicate among all vested parties (such as in regular Skype meetings, periodic e-mail updates, and so on).

\section{Ethics committee involvement}

Soliciting input from an impartial third party, such as an ethics committee, can help clarify even the thorniest problems and provide insights regarding direction, authorship and other issues as needed. Not intended to be a last resort but rather a dispassionate authority, an ethics committee can weigh the facts and chart a clear course through murky waters. An ethics committee is a valuable but underused resource for such situations.

\section{CONCLUSIONS}

Grant transfers can present unexpected challenges. To avert problems, minimize disputes and ensure that everyone's interests are best served, we propose that institutions develop guidelines and processes, based on standards identified in the ethical conduct of research and ICJME publication guidelines. These guidelines should help resolve three distinct issues: future financial support under a grant, control/recognition of the original ideas embodied in the grant, and expression/protection of the faculty member's right to academic freedom. We suggest the invocation of an institutional ethics or other oversight group, staffed in part or in whole by faculty, which can operate in tandem with administration (and the funding agency, if needed), to help resolve disputes at any level. 


\section{ACKNOWLEDGMENTS}

The authors wish to thank Lana Christian of CreateWrite Inc. for her expert editing assistance with this manuscript.

\section{FUNDING/SUPPORT}

None

\section{OTHER DISCLOSURES}

No conflicts of interest to report.

\section{REFERENCES}

1. Assembly Bill 609 , Chapter 789. State-funded research: State Department of Public Health. State of California. 2014.

2. Atkinson, R. D., Stewart, L. A. (2011). University Research Funding: The United States is Behind and Falling. The Information Technology \& Innovation Foundation.

3. Board of Trustees of Leland Stanford Junior University v. Roche Molecular Systems, Inc., et al. No. 09-1159. (2011). Retrieved from:

http://www.supremecourt.gov/opinions/10pdf/09-1159.pdf

4. Browning, D. (2014, January 26) Decline in federal grants threatens state research. Star Tribune. Retrieved from:

http://www.startribune.com/lifestyle/health/241990681.html

5. Bouville M. (2008). Plagiarism: Words and Ideas. Sci Eng Ethics. 14, 311-322. 
6. Council on Governmental Relations. (2001). Managing Externally Funded Programs at Colleges and Universities A Guideline to Good Management Practices.

7. Council on Governmental Relations. (2011a). A Tutorial on Technology Transfer in U.S. Colleges and Universities.

8. Council on Governmental Relations. (2011b). Access to, Sharing and Retention of Research Data: Rights \& Responsibilities.

9. Faust, D. G. The Role of the University in a Changing World. Presented at the Royal Irish Academy, Trinity College; Dublin, Ireland; June 30, 2010. Retrieved from: http://www.harvard.edu/president/speech/2010/role-university-changing-world

10. Government Accounting Office. (2013). Biomedical research: NIH should assess the impact of growth in indirect costs on its mission. Retrieved from: http://www.gao.gov/assets/660/658087.pdf

11. Harper, G. K. (2007). Copyright Crash Course: Who Owns What? University of Texas Libraries. Retrieved from: http://copyright.lib.utexas.edu/whoowns.html

12. Henderson, J. A., Smith, J. J. (2002). Academia, Industry and the Bayh-Dole act: an implied duty to commercialize.

13. International Committee of Medical Journal Editors. (n.d.) Defining the Role of Authors and Contributors. Retrieved from: http://www.icmje.org/recommendations/browse/roles-and-responsibilities/definingthe-role-of-authors-and-contributors.html

14. International Committee of Medical Journal Editors. (1991). Uniform Requirements for Manuscripts Submitted to Biomedical Journals. N Engl J Med. 324(6), 424-428. 
15. Lawrence, C., Gunther, G. (1990). Good Speech, Bad Speech. Stanford Lawyer. 24(1), 4-9.

16. Mangan, K. S., Blumenstyk, G. (2000, November 17). Colleges' Conflict-of-Interest Rules Are Criticized as Vague. The Chronicle of Higher Education. Retrieved from: http://chronicle.com.proxy2.ulib.iupui.edu/article/Colleges-Conflict-of-Interest/13975/

17. National Institutes of Health. (n.d.) NIH Peer Review: Grants and Cooperative Agreements. Retrieved from:

http://grants.nih.gov/grants/PeerReview22713webv2.pdf

18. National Institutes of Health. (2010a). Grants and Funding: NIH Grants Policy Statement Part II: Terms and Conditions of NIH Grant Awards. Retrieved from: http://grants.nih.gov/grants/policy/nihgps 2010/nihgps ch8.htm

19. National Institutes of Health. (2010b). Equipment under Grants. Retrieved from: http://grants.nih.gov/grants/policy/equipment faqs.htm

20. National Institutes of Health. (2013). Types of Grant Programs. Retrieved from: http://grants.nih.gov/grants/funding/funding_program.htm

21. National Institutes of Health. (2015). NIH Budget: Research for the People. Retrieved from: http://www.nih.gov/about/budget.htm

22. Office of Research Integrity; U.S. Dept. of Health and Human Services. (1994). ORI Provides Working Definition of Plagiarism. ORI Newsletter. 3(1), 5-6.

23. Sargent, J. F. Jr. (2013). Federal Research \& Development Funding: FY 2013. Congressional Research Service. 7-5700. R42410.

24. Shamoo A. E., Resnik, D. B. (2009). On Being a Scientist: A Guide to Responsible Conduct in Research. 3rd ed. Oxford, NY: Oxford University Press. 
25. Uniform requirements for manuscripts submitted to biomedical journals: Writing and editing for biomedical publication. (2010). J Pharmacol Pharmacother. 1(1), 42-58.

26. Who Owns Patent Rights: Employer or Inventor? (n.d.) Retrieved from:

http://www.nolo.com/legal-encyclopedia/who-owns-patent-rights-employerinventor.html

27.Zinner, D. E., Campbell, E. G. (2009). Life-Science Research within U.S. Academic Medical Centers. JAMA. 302(9), 969-976. 